\title{
Virus aetiology of certain cases of lacrimal obstruction
}

\author{
A. G. BOUZAS \\ Athens Public Hospital for Infectious Diseases, Greece
}

The aetiology of most cases of lacrimation due to stenosis or obstruction of the uppcr lacrimal drainage system is not yet known, but in some cases it is due to infection of the lacrimal puncta and canaliculi when virus disease is localized in the eyes and eyelids.

Attention has already been drawn to constriction and obstruction of the lacrimal puncta and canaliculi in ophthalmic vaccinia (Bouzas, I95o, 1962). Similar complications have been observed in herpes zoster ophthalmicus (Bouzas, I 964, I965), in herpes simplex of the eye, and in the Lyell syndrome (Bouzas and Drossos, I97I).

A systematic follow-up has been undertaken of ophthalmic involvement in various virus diseases in patients treated in Athens at the Infectious Diseases Hospital.

\section{Observations}

(a) Ocular involvement in vaccinia

Of 24 patients, five showed involvement of the lacrimal drainage system of the affected eye:

CASE I Obstruction of lower lacrimal punctum and stenosis of upper punctum and canaliculus.

CASE 2 Stenosis of upper and lower puncta and canaliculi.

CASE 3 Stenosis of lower punctum and canaliculus at its starting point with complete obstructions, and stenosis of upper punctum and canaliculus.

CASE 4 Obstruction of upper and lower puncta.

CASE 5 Stenosis of upper and lower puncta and canaliculi.

In all cases the condition was unilateral, and the following sequelae were noted: minor scars of the conjunctiva and the skin of the eyelids, permanent loss of the eyelashes at irregular intervals, and particularly permanent lacrimation.

\section{(b) Herpes zoster ophthalmicus}

Of nineteen patients all with conjunctivitis, four showed obvious signs of involvement of the upper lacrimal drainage system, and two others had permanent lacrimation.

CASE I Stenosis of upper and lower canaliculi with further obstruction 2 to $3 \mathrm{~mm}$. from the puncta.

CASE 2 Obstruction of lower and stenosis of upper punctum and canaliculus.

CASE 3 Stenosis of upper and lower puncta and canaliculi.

CASE 4 Stenosis of lower punctum and canaliculus and further obstruction $3 \mathrm{~mm}$. from the punctum. Stenosis of upper punctum and canaliculus. 
All four patients, after herpes zoster ophthalmicus had been cured, showed scars of the eyelids, permanent loss of some eyelashes and irregular tangling of others, as well asō permanent lacrimation.

\section{(c) Herpes simplex ophthalmicus}

Of twelve patients with ocular involvement during the course or the regression of a general $\frac{\overline{\bar{m}}}{\overline{0}}$ infectious disease, one presented stenosis of the lower punctum and canaliculus as well as $\mathbb{\Phi}_{\mathcal{Q}}$ obstruction $4 \mathrm{~mm}$. from the punctum. A retrospective survey of 29 earlier cases of herpetic keratitis, showed that three patients, over a period of months and years, had mild $\vec{\circ}$ lacrimation due to minor stenosis of the canaliculi.

\section{(d) Chickenpox}

Of 82 cases of chickeripox treated in the hospital because of the severity of the disease, 0 o:le young patient had mild lacrimation which persisted for 6 months after the attackabated. Clinical examination showed a mild bilateral stenosis of the canaliculi. Duringoo the course of the disease the patient presented conjunctivitis and scleritis.

(e) Conjunctivitis due to "viruses"

In three patients presenting clinical signs of bilateral conjunctivitis because of virus? infection, and sometimes with elements of sub-epithelial keratitis at various acute stages 3 of the disease, progressive stenosis and obstruction of the lower punctum was observed as well as mild stenosis of the upper punctum and canaliculus with subsequent permaneğt $\overrightarrow{0}$ lacrimation.

\section{Comment}

In infectious virus diseases, affection of the lacrimal gland is very rare, as reported byळ્ळ Nataf, Lepine, and Bonamour (1960) in herpes zoster ophthalmicus and by Zarrabi (1958) in herpes simplex.

Also relatively rare is affection of the lacrimal drainage system in virus diseases. Djakos (1950), Postic (1 953), and Scuderi (1958) reported lacrimal canaliculitis in cases of trachoma.

We have observed stenosis and obstruction of the lacrimal puncta and canaliculi in응. many other virus diseases (Bouzas, I960, I962, I964, I965; Bouzas and Drossos, I97 I).

The lacrimal canaliculi, because of the narrowness of the duct, only $0.5 \mathrm{~mm}$. according. to Wolff ( 1948 ), are easily subject to stenosis if they become inflamed, especially when the infection extends beyond the stratified squamous epithelium up to the rich elastic layer.

It is well known that, in infections of the conjunctiva by microbes, no stenosis of the lacrimal apparatus is observed; this may be because the infection does not reach the elastic layer, but in certain virus diseases the infection seems to extend deeper into the N epithelium and scarring leads to stenosis.

Observations similar to ours of stenosis and obstruction of the lacrimal system in virus diseases have been made by Keith (1968) and Sandford-Smith (1970) in herpes simplex and by Werb (1969) in smallpox and chickenpox.

In recent years, since 5-iodo-2'-deoxy uridine (IDU) has been used in the treatment of herpetic keratitis, Patterson, Fox, and seven others (1963) reported that, of 198 cases, two presented with stenosis of the lacrimal punctum, which they attributed to the drug. However, Sandford-Smith (1970) maintained that the stenosis was probably caused not苂 by the drug but by the herpes. 
Our own observations confirm those of Sandford-Smith, because lacrimation due to stenosis appeared with the first attacks of herpes before IDU was administered.

Since the same phenomenon is present in certain other diseases, in which there is only suspicion that a virus is responsible, such as Stevens-Johnson syndrome, Lyell syndrome, etc., this may be a further indication of aetiology.

\section{Summary}

Stenosis and obstruction of the lacrimal drainage system was observed in cases of ocular vaccinia, herpes zoster ophthalmicus, ocular herpes simplex, chickenpox, and virus conjunctivitis. Many cases of lacrimation due to stenosis or obstruction of the lacrimal puncta and canaliculi, which are generally regarded as of unknown aetiology, may be explained by the presence of virus infection.

\section{References}

Bouzas, A. (1960) Bull. Soc. franç. Ophtal., 73, $43 \mathrm{I}$

(1962) Arch. Soc. Ophtal. Grèce Nord, I 1, 126

(1964) Bull. Soc. fran६. Ophtal., 77, I 7 I

(1965) Amer. 7. Ophthal., 6o, 7 I 3

and Drossos, c. (I97 I) Ann. Oculist. (Paris), 204, I 55

DJACOS, C. (1950) Ibid., 183, I 35

KeITH, C. G. (1968) Amer. 7. Ophthal., 65, 70

nAtaf, R., LÉPine, P., and bonamour, G. (1960) "Oeil et Virus". Masson, Paris

PATterson, A., FoX, A. D., DAVies, G., maGuire, C., holmes Sellers, P. J., Wright, P., Rige, N. S. C.,

COBB, B., and JONES, B. R. (1963) Trans. ophthal. Soc. U.K., 83, 583

postic, s. (1953) Arch. Ophtal., 13, 209

SCUDERI, G. (1958) Riv. ital. Tracoma., ro, Süppl., p. 123

SANDFORD-SMITH, J. H. (1970) Brit. F. Ophthal., 54, 456

WERB, A. (1969) In "Corneo-plastic Surgery: Proc. II. int. Corneo-plastic Conf., London, 1967",

P. V. Rycroft, p. 87. Pergamon, Oxford

WOLFF, E. (1948) "The Anatomy of the Eye and Orbit", 3rd ed. Lewis, London

zarrabi, c. (1958) Arch. Ophtal., 18, 57 